\title{
The effect of architectural form on the earthquake behavior of symmetric RC frame systems
}

\author{
Tugba Inan $^{1}$, Koray Korkmaz and Ismail H. Cagatay ${ }^{* 2}$ \\ ${ }^{1}$ Department of Architecture, Izmir Institute of Technology, Izmir, Turkey \\ ${ }^{2}$ Department of Civil Engineering, University of Cukurova, Adana, Turkey
}

(Received April 23, 2012, Revised November 05, 2013, Accepted November 11, 2013)

\begin{abstract}
In this study, structural irregularities in plan, which has a considerable effect on earthquake behavior of buildings, have been investigated in detail based on Turkish Earthquake Code 2007. The study consists of six main parametric models and a total of 144 sub-models that are grouped based on RC structural systems such as frame, frame + rigid core, frame with shear wall, and frame with shear wall + rigid core. All models are designed to have both symmetrical plan geometry and regular rigidity distribution. Changes in the earthquake behavior of buildings were evaluated according to the number of storeys, number of axes and the configuration of structural elements. Many findings are obtained and assessed as a result of the analysis for each structural irregularity. The study shows that structural irregularities can be observed in completely symmetric buildings in terms of plan geometry and rigidity distribution.
\end{abstract}

Keywords: earthquake; architectural form; structural irregularities; RC buildings

\section{Introduction}

Turkey is a tectonically active country and suffers from earthquakes at frequent intervals, which cause considerable loss of life and property, and has negative impacts on the national economy (Sezen et al. 2000). It faces with earthquakes in the future as well which are presumably turned to disasters by the collapses of the structures. Van earthquake is a significant indicator for this condition with a magnitude of $7.2 \mathrm{M}_{\mathrm{w}}$ that shake the city on 23 October 2011. Therefore, designing resistant buildings against earthquake loads is a vital need for Turkey.

Architectural design decisions have a significant effect on earthquake behavior of structure that influences the seismic performance of the building due to the particularly building and structural system configuration issues (Charleson 2008, Inan 2010). When many collapsed or heavily damaged multi-storey reinforced concrete $(\mathrm{R} / \mathrm{C})$ buildings were investigated after the recent earthquake in Turkey, it was seen that failures on buildings start at the beginning of the architectural design phase. As a consequence, there is a strong relationship between the architectural design of building and its earthquake safety (Tezcan and Alhan 2001, Özmen and Unay 2007, Inan et al. 2012).

Regular configuration and appropriate design decisions should be developed to provide better

*Corresponding author, Professor, E-mail: hcagatay@cukurova.edu.tr 
seismic behavior, which means ideal or optimum configuration for overcoming with devastating earthquake loads (Cagatay 2005, Stefano and Pintucchi 2008, Inan and Korkmaz 2011).

All contemporary earthquake codes suggest that design and construction of irregular buildings should be avoided. Turkish Earthquake Code (TEC-2007) (Specification for Buildings to be Built in Seismic Zones 2007), is a contemporary earthquake code that presents several suggestions and limitations. It states that structural system should be arranged symmetrical or nearly symmetrical in plan and torsional irregularity and soft storey irregularity should preferably be avoided.

Earthquake behavior of reinforced concrete structures has always been a remarkable subject and examined by many researchers in order to prevent structural irregularities (Dimova and Alashki 2003, Ganjavi et al. 2007, Athanassiadou 2008, Belmouden and Lestuzzi 2009, Cagatay 2010, Chen et al. 2012, Wang et al. 2012). Özmen (2004) investigated the effect of torsional irregularity for a series of walled and framed sample structures with different shear wall configuration under earthquake loading, and concluded that maximum torsional irregularity values are obtained when the both number of axes and the number of stories are low. Bal et al. (2008) investigated and evaluated geometrical, functional and material properties of the building stock in the northern Marmara Region, particularly around Istanbul, for use in loss estimation models and other types of statistic- or probability-based studies.

In this study, interaction between architectural design and structural configuration is examined. This is a significant issue because the same damage picture emerges after each earthquake, but afterwards it is forgotten. The study examines structural irregularity conditions with the models having both symmetric plan geometry and rigidity distribution. Approximately all of the studies, which previously have been done related to structural irregularities, focus on asymmetric plan geometries with irregular rigidity distribution. Apart from that type of studies, this study basically focuses on completely symmetric buildings in terms of both plan geometry and rigidity distribution. Because, the goal of the study is to determine the best one among the better designs instead of better one among the poor designs.

\section{Structural irregularities}

The definition of irregular buildings described in the TEC-2007 as the buildings whose design and construction should be avoided due to their unfavorable seismic behavior. Irregularities in plan consist of three different type of structural irregularity. The torsional irregularity denoted as A1 and soft storey irregularity denoted as B2 are the significant irregularities that they have determinative role on the earthquake calculation methods of structures (TEC-2007).

In TEC-2007, methods to be used for the seismic analysis of buildings and building-like structures are Equivalent Seismic Load Method, Mode-Superposition Method, and Analysis Methods in the Time Domain. While the application limits of the equivalent seismic load method depends on irregularity types A1, B2 and total height limits, the last two methods may be used for the seismic analysis of all buildings and building-like structures.

\subsection{Torsional Irregularity (A1)}

The case where torsional irregularity factor $\eta_{\mathrm{bi}}$ which is defined for any of the two orthogonal earthquake directions as the ratio of the maximum storey drift at any storey to the average storey drift at the same storey in the same direction, is greater than 1.20 , as follows 


$$
\eta_{\mathrm{bi}}=\frac{(\Delta i) \max }{(\Delta i) \operatorname{avg}}>1.20
$$

In the case of the torsional irregularity coefficient $\left(\eta_{\mathrm{bi}}\right)$ is greater than 1.20 at any storey of the structure, torsional irregularity occurs in that structure. The $\pm 5 \%$ additional eccentricity is considered in the displacement computations on both earthquake directions.

\subsection{Interstorey stiffness irregularity (Soft storey) (B2)}

Soft storey irregularity is defined in the TEC-2007 as the case where in each of the two orthogonal earthquake directions, stiffness irregularity factor $\eta_{\mathrm{ki}}$, which is defined as the ratio of the average storey drift at any storey to the average storey drift at the storey immediately above or below, is greater than 2.00. Moreover, storey drifts should be calculated by considering the effects of $\pm 5 \%$ additional eccentricities.

$$
\begin{aligned}
& \eta_{\mathrm{ki}}=\left(\Delta_{\mathrm{i}} / \mathrm{h}_{\mathrm{i}}\right)_{\text {ave }} /\left(\Delta_{\mathrm{i}+1} / \mathrm{h}_{\mathrm{i}+1}\right)_{\mathrm{ave}}>2.00 \text { or } \\
& \eta_{\mathrm{ki}}=\left(\Delta_{\mathrm{i}} / \mathrm{h}_{\mathrm{i}}\right)_{\text {ave }} /\left(\Delta_{\mathrm{i}-1} / \mathrm{h}_{\mathrm{i}-1}\right)_{\text {ave }}>2.00
\end{aligned}
$$

where $\Delta_{i}, d_{i}$ represents storey drift of $i$ 'th storey of building, lateral displacements, respectively, and $h_{i}=$ height of $i$ 'th storey of building.

\section{Numerical analysis}

In this study, structural irregularities were evaluated according to the TEC-2007. Many parametric studies were developed for this aim. The changes in parameters such as torsional irregularity coefficient $\left(\eta_{\mathrm{bi}}\right)$, stiffness irregularity coefficient $\left(\eta_{\mathrm{ki}}\right)$, maximum effective storey drift, interstorey drift and second order effect are compared in each parametric model.

All models are designed having both symmetrical and regular plan geometry and rigidity distribution. The aim is to explore the effective role of the structural elements type, their location in the plan and their sufficiency in terms of rigidity, strength and stability in determining the earthquake behavior of structures via the symmetrical plan geometry and rigidity distribution. All models are generated based on defined variables and their earthquake behavior is compared on the basis of their structural irregularities, following obtained results are discussed.

The study consists of six main parametric models called Model A-F as seen in Fig. 1. It totally consists of 144 sub-models. Each model has a beam span of $5 \mathrm{~m}$ with different number of bays in both $\mathrm{X}$ and $\mathrm{Y}$ directions. The models are assumed to be in the $1^{\text {st }}$ degree earthquake zone. They are designed with C30 class concrete and S420 class steel. Project and TEC-2007 parameters, which are used in the cases, are described in the Table 1 as follows:

In this study, various R/C structures are designed to examine the earthquake behavior of structures based on structural irregularities defined TEC-2007. Therefore, R/C structural system types, which are commonly used in Turkey, are grouped based on R/C structural systems such as: a. Frame System, b. Frame System + Rigid Core, c,d. Shear-Frame System, and e,f. Shear-Frame System + Rigid Core. 
Table 1 Project and TEC-2007 parameters

\begin{tabular}{cc}
\hline \hline Project parameters of the models & TEC-2007 parameters \\
\hline Maximum storey Number: 20 & Earthquake zone: 1 \\
Storey height: $2.80 \mathrm{~m}$ & Soil class: Z2 \\
Beam span: $5 \mathrm{~m}$ & Earthquake zone factor: 0.4 \\
Beams: $300 / 600 \mathrm{~mm}$ & Building importance factor: 1 \\
Columns: $600 / 600 \mathrm{~mm}$ & Concrete class: C30 \\
Shear wall: $250 / 5000 \mathrm{~mm}$ & Steel class: S420 \\
Slab thickness: $150 \mathrm{~mm}$ & Ductility level: high, R: 6.00 \\
& Live load factor: 0.3 \\
\hline
\end{tabular}

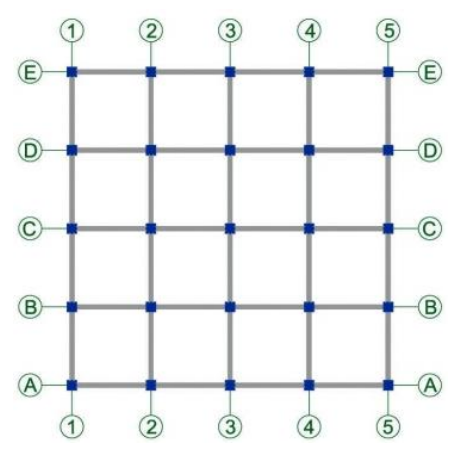

Model A: frame systems

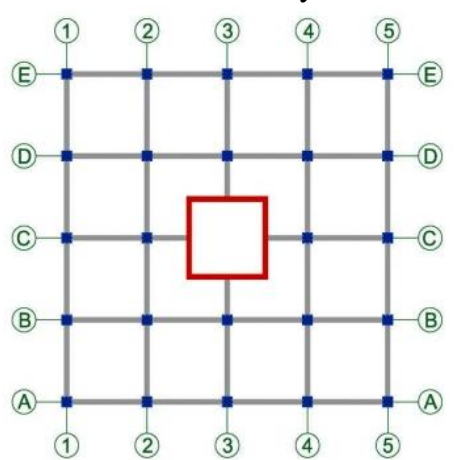

Model B: Frame system+rigid Core

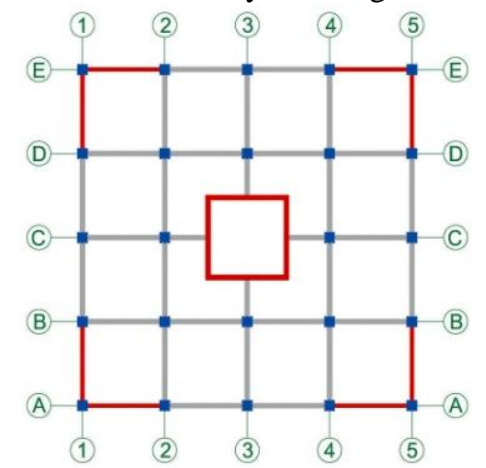

Model C: Shear-frame system (1)

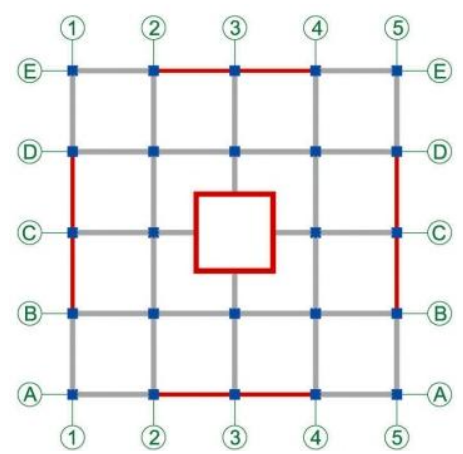

Model D: Shear-frame-system (2)

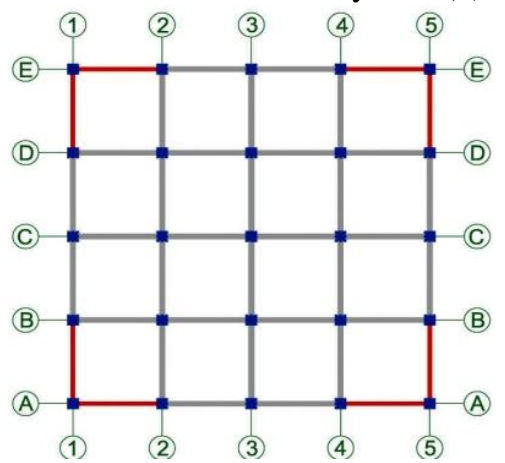

Model E: Shear-frame-system (3)

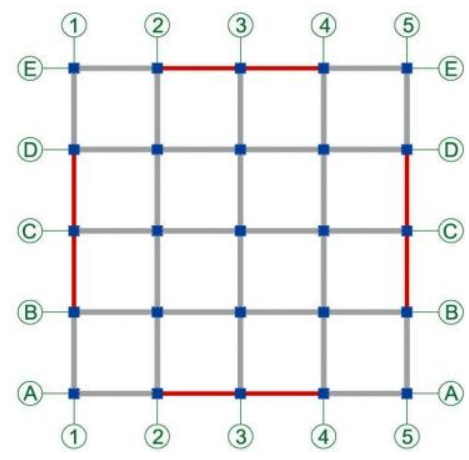

Model F: shear-frame system (4)

Fig. 1 Structural models 


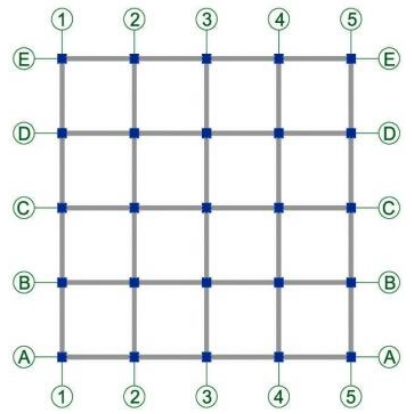

(a) A-20

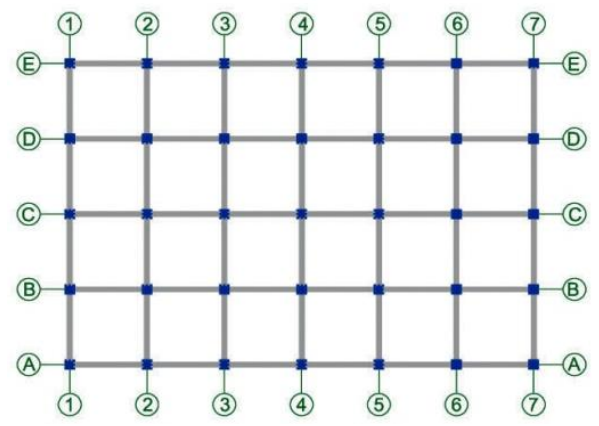

(b) A-30

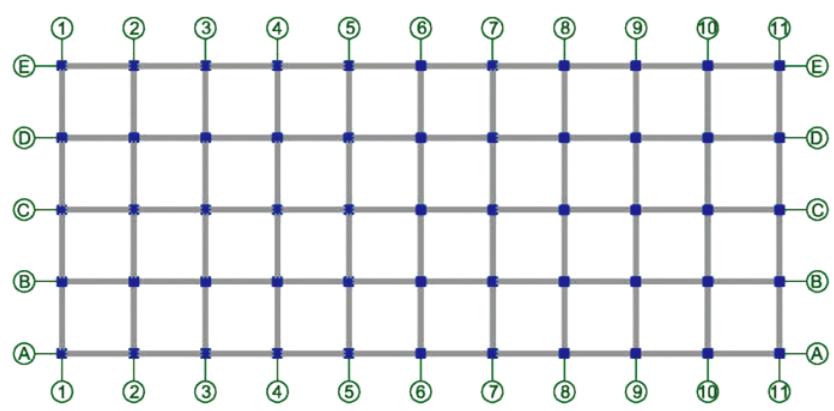

(c) A-50

Fig. 2 Structural plans of parametric model A and its sub models. a) A-20, b) A-30, c) A-50

For each selected R/C structural system type, three models which have a dimension of $20 \mathrm{~m} \times$ $20 \mathrm{~m}, 20 \mathrm{~m} \times 30 \mathrm{~m}$, and $20 \mathrm{~m} \times 50 \mathrm{~m}$ are generated by increasing the number of axis along the $\mathrm{X}$ direction. These main models are coded differently in each parametric model without changing dimensions. The main variables can be listed as follows

- R/C structural system type (Model A-F) (refer to Fig. 1)

- The number of axis $(5,7$, and 11) (refer to Fig. 2)

- The number of storey (1S, 3S, 5S, 8S, 10S, 12S, 15S, 20S)

All models are analyzed by IdeCAD which is a 3D structural analysis software (IdeCad 2010). Moreover, all the necessary controls are made in accordance with the TEC-2007 and the building code requirements for reinforced concrete, TS-500 (2000).

\subsection{Model A: frame systems}

In this model, the structure is designed as a frame system. Each beam span has a length of $5 \mathrm{~m}$. The model not only has symmetrical and regular plan geometry, but it also has regular rigidity distribution. The parametric models of A are shown in Fig. 2, and it consists of three sub-models such as A-20 $(20 \mathrm{~m} \times 20 \mathrm{~m})$, A-30 $(20 \mathrm{~m} \times 30 \mathrm{~m})$, and A-50 $(20 \mathrm{~m} \times 50 \mathrm{~m})$. Earthquake behavior of frame systems is investigated by changing the number of storey and axis. The analysis results shown in Table 2 and Fig. 3, are discussed by comparing each result of A-20, A-30 and A-50.

The analysis shows that, the maximum value of effective storey drift is changing depending on parametric models. While the maximum values of effective storey drift in model A-20 is $16.87 \mathrm{~mm}$ 


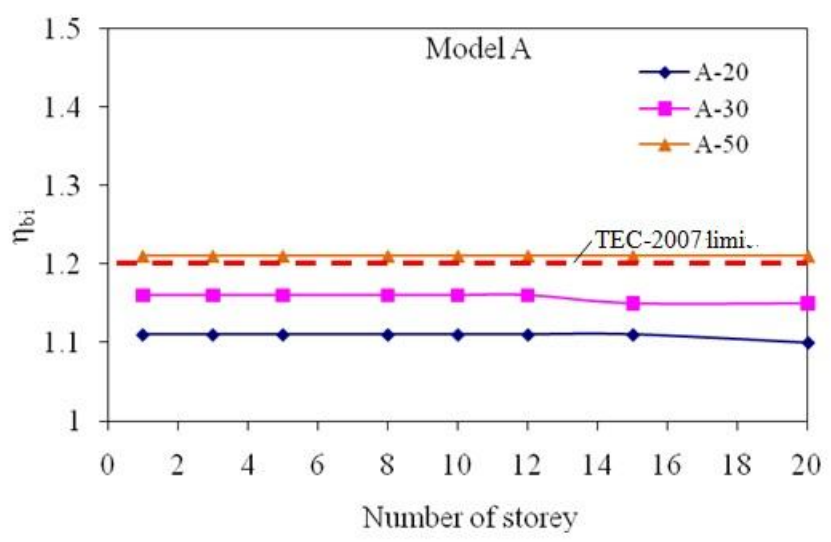

Fig. 3 Changing coefficient $\left(\eta_{\mathrm{bi}}\right)$ with the number of storey and different sub-model

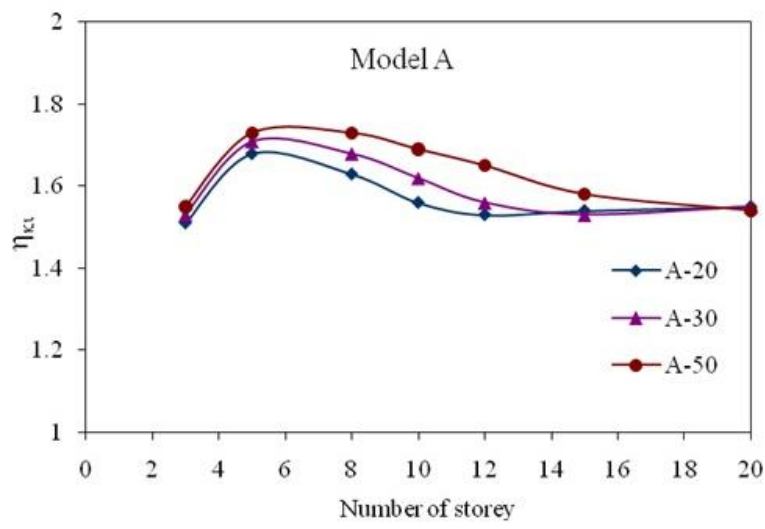

Fig. 4 Changing coefficient $\left(\eta_{\mathrm{ki}}\right)$ with the number of storey and different sub-model

, it is $19.31 \mathrm{~mm}$ in A-50. The limit values in terms of interstorey drifts and second order effect are not exceeded. These values increase from the one-storey model to the 20 -storey model. Besides, they are gradually increase from the ground floors to the upper floors of model A-20, A-30, and A50 .

Based on the analysis result- report, the maximum torsional irregularity coefficient $\left(\eta_{\mathrm{bi}}\right)$ is obtained 1.11 in A-20, 1.16 in A-30, and 1.21 in A-50. It is observed that if the number of storey of the parametric models in A increase, the maximum torsional irregularity coefficient will decrease. Torsional irregularity coefficients not only decrease from the one-storey model to the 20-storey model, but they also decrease within the storeys of each sub-model of parametric models of A - for ex. the values are higher on the $1^{\text {th }}$ floor of a 5-storey model than its $5^{\text {st }}$ floor. Besides, torsional irregularity coefficients increase from parametric model A-20 to A-50. It can be concluded that if the number of axis increase, the torsional irregularity coefficients will increase in parametric model A. Though, there is not torsional irregularity in A-20 and A-30, there is torsional irregularity in A-50, as seen in Fig. 3. The maximum torsional irregularity coefficient is obtained as 1.21 in A50 . 
Table 2 Analysis results of parametric model A

\begin{tabular}{ccccccc}
\hline \hline Sub model & \# of Storey & $(\delta \mathrm{i}) \max$ & $\delta$ max/hi $\leq 0.02$ & $\theta \leq 0.12$ & $\eta_{\mathrm{bi}}<1.20$ & $\eta_{\mathrm{ki}}<2.00$ \\
\hline & 1 & 1.38 & 0.0005 & 0.0004 & 1.11 & - \\
& 3 & 4.91 & 0.0018 & 0.0015 & 1.11 & 1.51 \\
A-20 & 5 & 9.25 & 0.0034 & 0.0032 & 1.11 & 1.68 \\
& 8 & 12.98 & 0.0048 & 0.0056 & 1.11 & 1.63 \\
& 10 & 13.92 & 0.0052 & 0.0073 & 1.11 & 1.56 \\
& 12 & 14.69 & 0.0054 & 0.0090 & 1.11 & 1.53 \\
& 15 & 15.62 & 0.0058 & 0.0116 & 1.11 & 1.54 \\
& 20 & 16.87 & 0.0062 & 0.0162 & 1.10 & 1.55 \\
\hline & 1 & 1.50 & 0.0006 & 0.0004 & 1.16 & - \\
A-30 & 5.33 & 0.0020 & 0.0016 & 1.16 & 1.53 \\
& 5 & 10.05 & 0.0037 & 0.0033 & 1.16 & 1.71 \\
& 8 & 13.89 & 0.0051 & 0.0059 & 1.16 & 1.68 \\
& 10 & 14.88 & 0.0055 & 0.0076 & 1.16 & 1.62 \\
& 12 & 15.71 & 0.0058 & 0.0094 & 1.16 & 1.56 \\
& 15 & 16.70 & 0.0062 & 0.0120 & 1.15 & 1.53 \\
& 20 & 18.01 & 0.0067 & 0.0169 & 1.15 & 1.55 \\
\hline & 1 & 1.63 & 0.0006 & 0.0004 & 1.21 & - \\
& 3 & 5.80 & 0.0021 & 0.0016 & 1.21 & 1.55 \\
& 5 & 10.92 & 0.0040 & 0.0034 & 1.21 & 1.73 \\
& 15 & 14.89 & 0.0055 & 0.0061 & 1.21 & 1.73 \\
& 10 & 15.95 & 0.0059 & 0.0079 & 1.21 & 1.69 \\
& 12 & 16.84 & 0.0062 & 0.0097 & 1.21 & 1.65 \\
& 15 & 17.91 & 0.0066 & 0.0124 & 1.21 & 1.58 \\
& 19.31 & 0.0072 & 0.0174 & 1.21 & 1.54 \\
\hline
\end{tabular}

Stiffness irregularity coefficient $\left(\eta_{\mathrm{ki}}\right)$ is within the normal ranges in the sub-models of parametric model A. It changes between 1.51 and 1.68 in A-20, 1.53 and 1.71 in A-30, 1.54 and 1.73 in A-50. There is an increase in the stiffness irregularity coefficients from A-20 to A-50. As the coefficients remain under the limit coefficient of 2.00, the soft storey coefficient is agreeable. The highest stiffness irregularity coefficient is found as 1.73 in the five and eight-storey sub models of A-50, as seen in Fig. 4. On the other hand, there is not a balanced increase or decrease within the storeys of each of the different storey parametric models of A from the ground floor to the upper floors.

\subsection{Model B: frame system+ rigid core}

In this model, the structure is designed as a frame system. Apart from the parametric Model A, a rigid core added in the centre of the structure to maintain the symmetry condition. The parametric models of B, which have three sub models such as B-20, B-30 and B-50, are shown in Fig. 5. The effects of the central rigid core on earthquake behavior are investigated by changing the number stories and axis. The analysis results were not given in a Table but given in Figs. 6-7 due to the space limitation.

The analysis shows that, while the maximum value of effective storey drift in parametric model B-20 is obtained as $14.27 \mathrm{~mm}$, it is $15.97 \mathrm{~mm}$ in parametric model B-30 and $17.97 \mathrm{~mm}$ in B-50. 


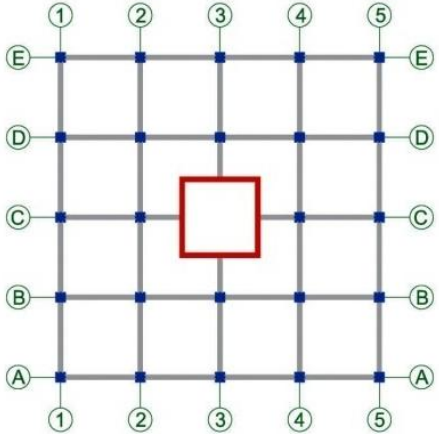

(a) B-20

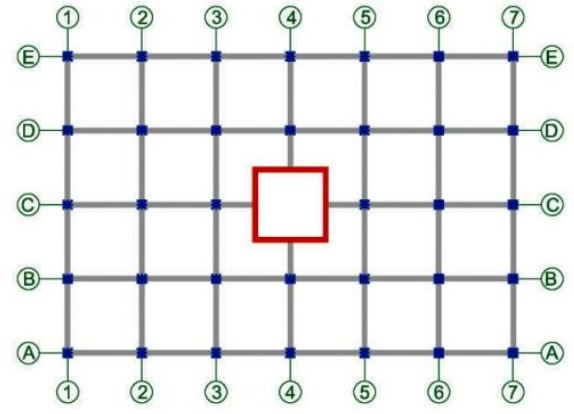

(b) B-30

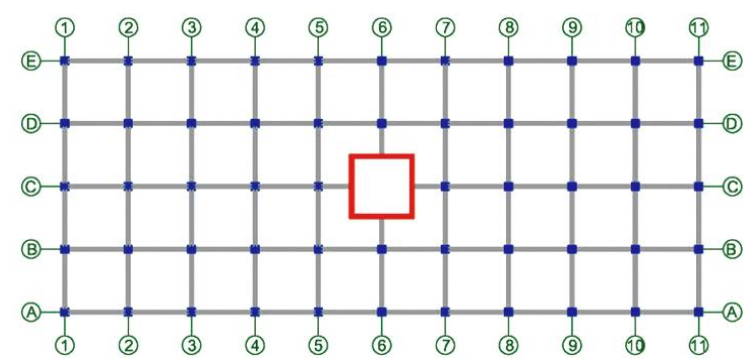

(c) B-50

Fig. 5 Structural plans of parametric Model B and its sub models. (a) B-20, (b) B-30, (c) B-50

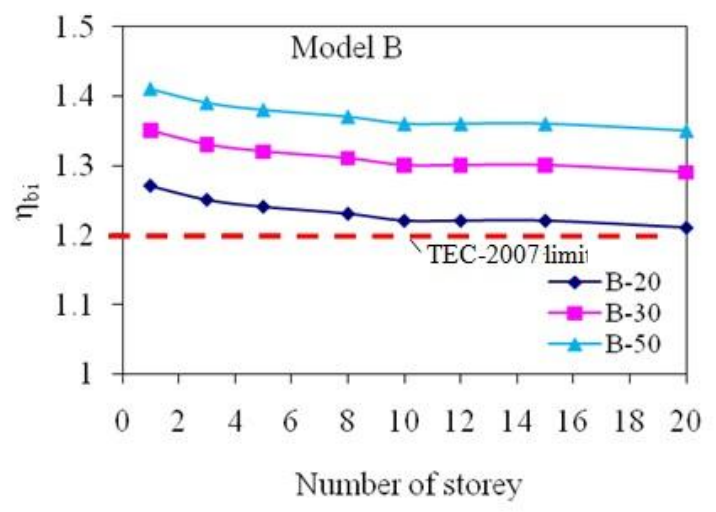

Fig. 6 Changing coefficient $\left(\eta_{\mathrm{bi}}\right)$ with the number of storey and different sub-model

The limit values in terms of interstorey drifts and second order effect are not exceeded. These values increase from the one-storey model to the 20 -storey model. Besides, they are gradually increase from the ground floors to the upper floors of model B-20, B-30, and B-50.

The maximum torsional irregularity coefficient $\left(\eta_{\mathrm{bi}}\right)$ is 1.27 in B-20, 1.35 in B-30 and 1.41 in B-50. It is noticed that torsional irregularity coefficients in all models of $\mathrm{B}\left(\eta_{\mathrm{bi}}\right)$ is greater than the limit value of 1.20, as seen in Fig. 6. As the rigid core is near to the gravity centre, it causes a considerable increase in the torsional irregularity coefficients. Torsional irregularity coefficients not only decrease from the one-storey model to the 20 -storey model, but they also decrease within 
the storeys of each sub-model of parametric models of B. Additionally, as going from B-20 to B50 , the torsional irregularity coefficients gradually increase.

Stiffness irregularity coefficient $\left(\eta_{\mathrm{ki}}\right)$ is under the limit value of 2.00 in the sub-models of B, as seen in Fig. 7. For this reason, there is no stiffness irregularity in parametric model B. The range varies between 1.47 and 1.87 in B-20, 1.44 and 1.81 in B-30 and 1.40 and 1.74 in B-50. There is a decrease in the maximum stiffness irregularity coefficients from B-20 to B-50. The highest stiffness irregularity coefficient is obtained as 1.87 in the 20 -storey parametric model of B-20. Furthermore, it can be concluded that if the number of storey in parametric model B increase, the maximum soft storey coefficient will gradually increase in each parametric model of B.

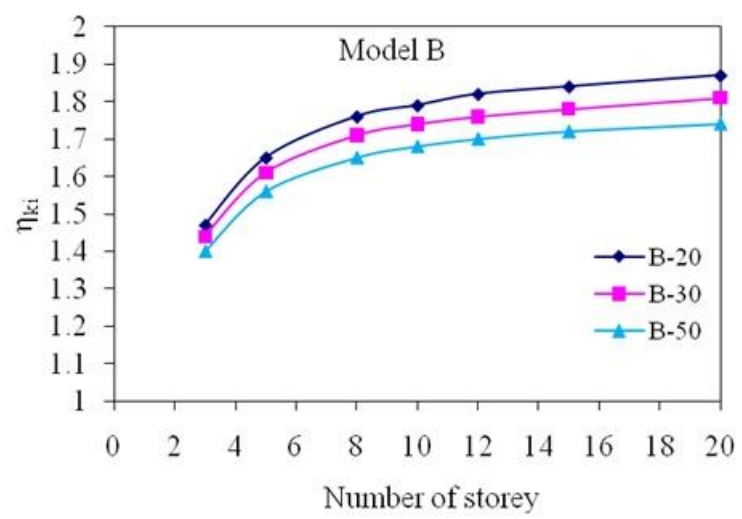

Fig. 7 Changing coefficient $\left(\eta_{\mathrm{ki}}\right)$ with the number of storey and different sub-model

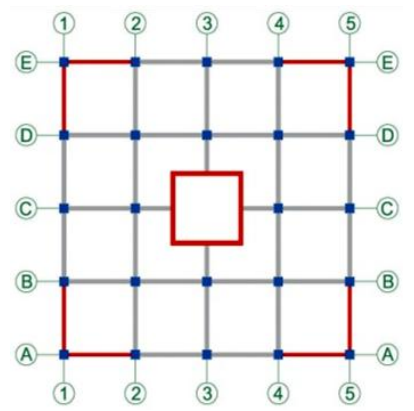

(a) $\mathrm{C}-20$

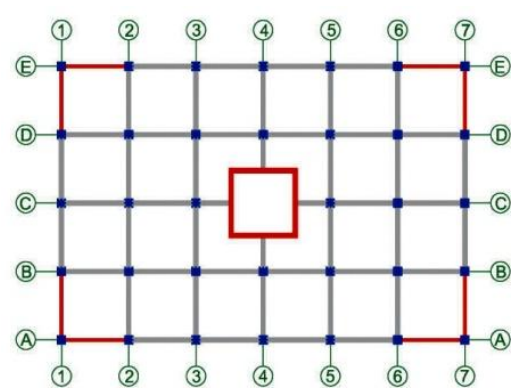

(b) C-30

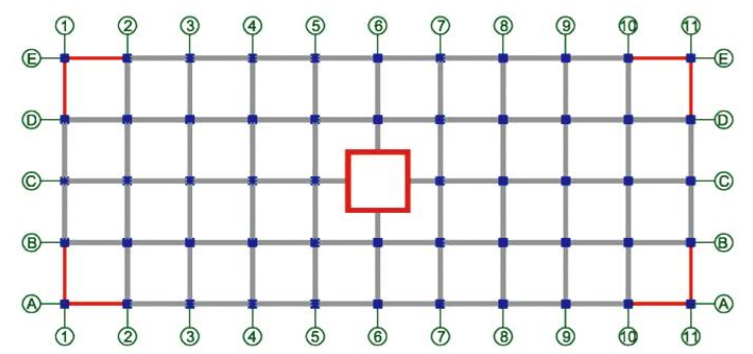

(c) $\mathrm{C}-50$

Fig. 8 Structural plans of parametric model C and its sub models. a) C-20, b) C-30, c) C-50 


\subsection{Model C: shear-frame system (1)}

The parametric model $\mathrm{C}$ is designed as a shear-frame system. Apart from the parametric model $\mathrm{B}$, four L-shaped shear walls are placed on the corners of the structure without removing the rigid core (Fig. 8). The effects of shear walls located on the corners of the structure are examined with the effects of rigid core.

While the maximum value of effective storey drift in parametric model C-20 is $11.41 \mathrm{~mm}$, it is $13.02 \mathrm{~mm}$ in C-30 and $15.03 \mathrm{~mm}$ in C-50. Interstorey drifts and second order effect coefficients defined in the TEC-2007 are not exceeded. These values gradually increase from the one-storey model to 20-storey model.

The maximum torsional irregularity coefficient $\left(\eta_{\mathrm{bi}}\right)$ is obtained as 1.08 in parametric model C20, 1.11 in C-30 and 1.17 in C-50, as seen in Fig. 9. Moreover, an increase in the number of storey

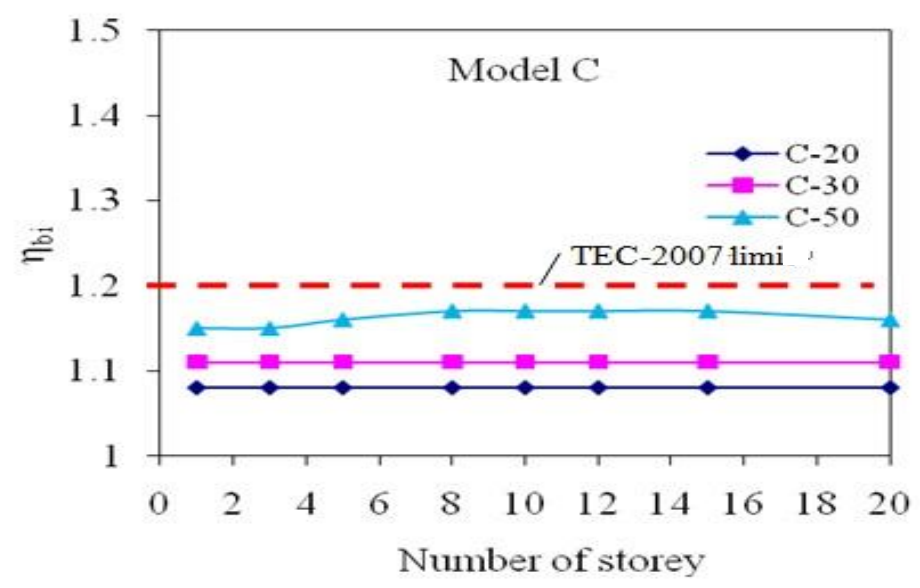

Fig. 9 Changing coefficient $\left(\eta_{\mathrm{bi}}\right)$ with the number of storey and different sub-model

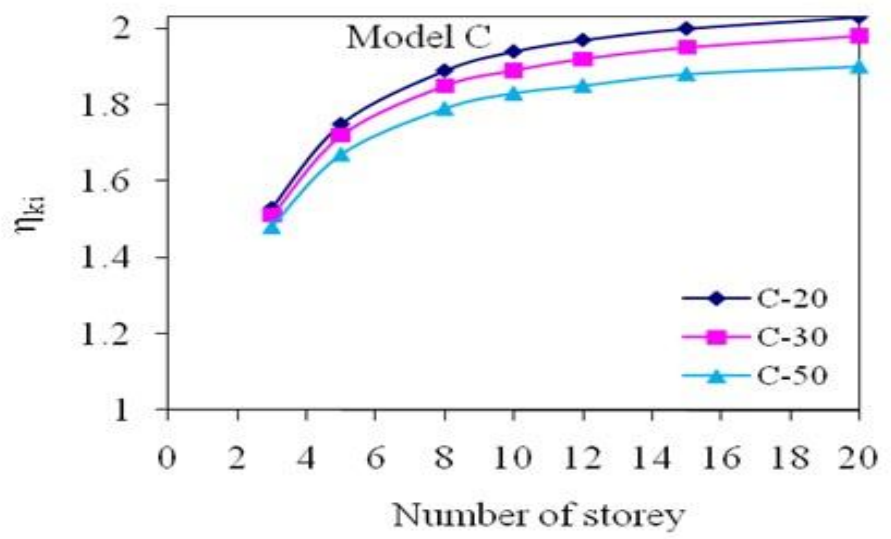

Fig. 10 Changing coefficient $\left(\eta_{\mathrm{ki}}\right)$ with the number of storey and different sub-model 
does not create a regular change in the maximum torsional irregularity coefficients between stories in sub-models of $\mathrm{C}$. Besides, torsional irregularity coefficients increase from parametric model C20 to C-50. There is not torsional irregularity in all models of parametric model C.

Stiffness irregularity coefficient $\left(\eta_{\mathrm{ki}}\right)$ gets higher values in the parametric models of $\mathrm{C}$. The range varies between 1.53 and 2.03 in C-20, 1.51 and 1.98 in C-30 and 1.48 and 1.90 in C-50.

There is a decrease in the maximum stiffness irregularity coefficient from C-20 to C-50. If the numbers of axis increase, the maximum soft storey irregularity coefficients will decrease. For instance, while the parametric model C-20 has soft storey irregularity, there is not in C-30 and C50. However, they are close to the limit coefficient of stiffness irregularity. The maximum stiffness irregularity coefficient is obtained as 2.03 in the 20-storey sub-model of C-20, as seen in Fig. 10. Furthermore, it is realized that if the number of storeys in parametric model $\mathrm{C}$ increases, the maximum soft storey coefficient will gradually increase from one storey model to the 20 -storey model.

\subsection{Model D: shear-frame system (2)}

In this model, the structure is designed as a shear-frame system like in the parametric model C. Apart from the parametric model C, four I-shaped shear walls are placed in the middle of the outer axis of the structures without removing the rigid core as illustrated in Fig. 11. The contributions of shear walls located in the middle of the outer axis are examined in terms of earthquake behavior.

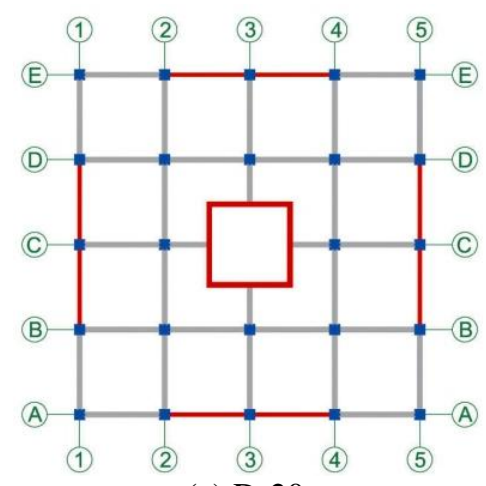

(a) D-20

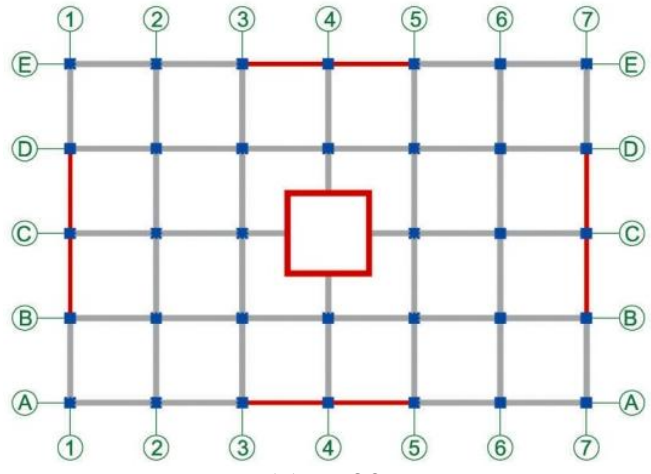

(a) D-30

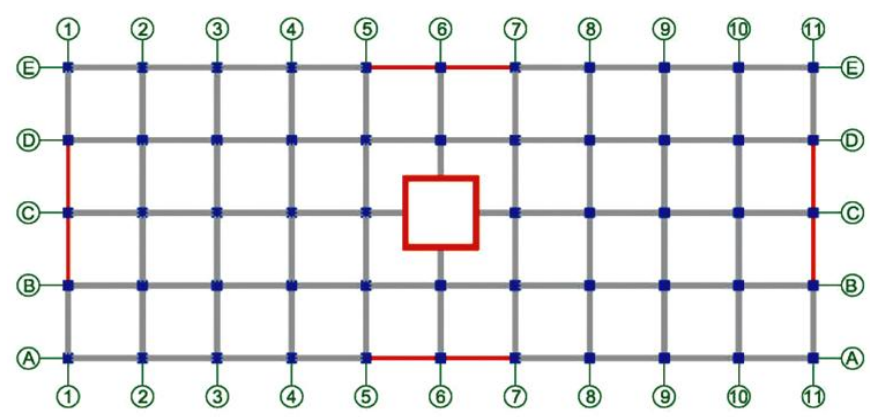

(c) D-50

Fig. 11 Structural plans of parametric model D and its sub models. (a) D-20, (b) D-30, (c) D-50 


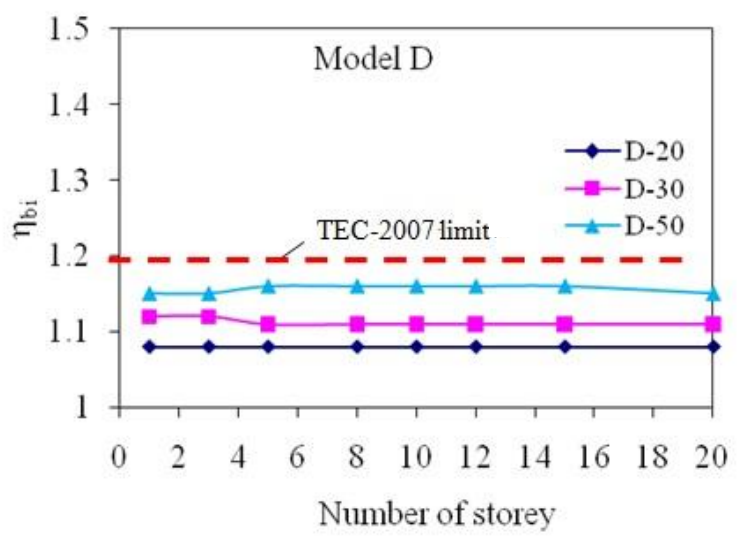

Fig. 12 Changing coefficient $\left(\eta_{\mathrm{bi}}\right)$ with the number of storey and different sub-model

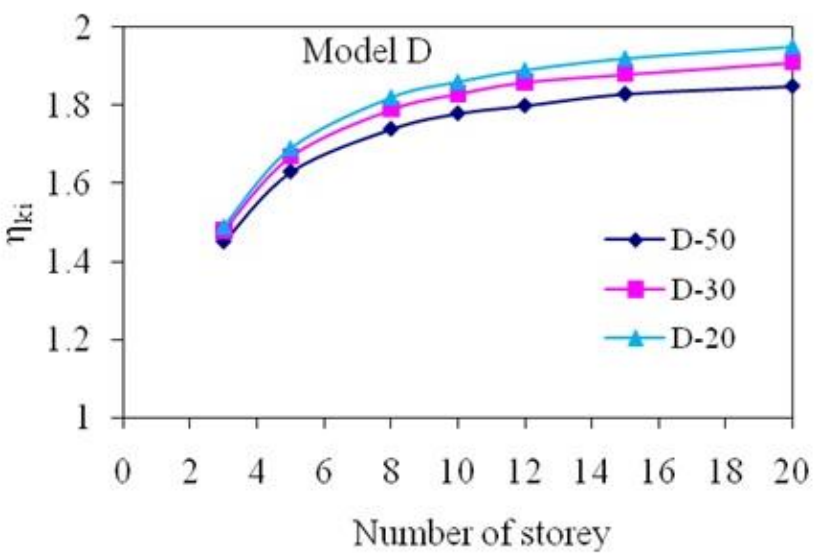

Fig. 13 Changing coefficient $\left(\eta_{\mathrm{ki}}\right)$ with the number of storey and different sub-model

It is observed that the maximum coefficient of effective storey drift in parametric model D-20 is $10.23 \mathrm{~mm}, 11.85 \mathrm{~mm}$ in D-30 and $14.00 \mathrm{~mm}$ in D-50. The interstorey drifts coefficients and second order effect coefficients are not exceeded. These values increase from the one-storey model to the 20-storey model. Besides, they are gradually increase from the ground floors to the upper floors of model D-20, D-30, and D-50.

The maximum torsional irregularity coefficient $\left(\eta_{\mathrm{bi}}\right)$ is 1.08 in D-20, 1.12 in D-30 and 1.16 in D-50. It is noticed that if the number of storey in parametric models of D increases, a constant behavior in the maximum torsional irregularity coefficients are not observed. Besides, torsional irregularity coefficients increase from parametric model D-20 to D-50. Therefore, it can be concluded that if the number of axis increase in parametric model $\mathrm{D}$, the torsional irregularity coefficients will increase. There is not torsional irregularity in all models of parametric model D, as seen in Fig. 12.

Stiffness irregularity coefficient $\left(\eta_{\mathrm{ki}}\right)$ shows an acceptable range in the parametric models of D. The range varies between 1.49 and 1.95 in D-20, 1.48 and 1.91 in D-30 and 1.45 and 1.85 in D-50. There is a decrease in the maximum stiffness irregularity coefficient from D-20 to D-50 (Fig. 13). 
There is not stiffness irregularity in parametric model D. The maximum stiffness irregularity coefficient is gained as 1.95 in the 20 -storey parametric model of D-20. As a result, if the number of storey in parametric model D increases, the maximum soft storey coefficient will gradually increase in each models of parametric model D.

\subsection{Model E: Shear-frame system (3)}

In this model, the structure is designed as a shear-frame system like the parametric models $\mathrm{C}$ and D. Apart from the parametric model C, the rigid core is removed in parametric model E. Lshaped shear walls are located on the corners of the structure (Fig. 14). The effects of shear walls which are located on the corners of the structure are investigated without a central rigid core.

According to the structural irregularities report, while the maximum value of effective storey drift in parametric model E-20 is $12.44 \mathrm{~mm}$, it is $13.95 \mathrm{~mm}$ in E-30 and $15.99 \mathrm{~mm}$ in E-50. The limit values in terms of interstorey drifts and second order effect are not exceeded. All that values gradually increase from one-storey model to 20 -storey model.

The maximum torsional irregularity coefficient $\left(\eta_{\mathrm{bi}}\right)$ is obtained as 1.06 in E-20, 1.10 in E-30 and 1.16 in E-50 (Fig. 15). Torsional irregularity coefficients not only decrease from the onestorey model to the 20-storey model, but they also decrease within the storeys of each sub-model of parametric models of $\mathrm{E}$. Besides, torsional irregularity coefficients increase from parametric model E-20 to E-50. While there is not torsional irregularity in E-20 and E-30, it is observed in E50 .

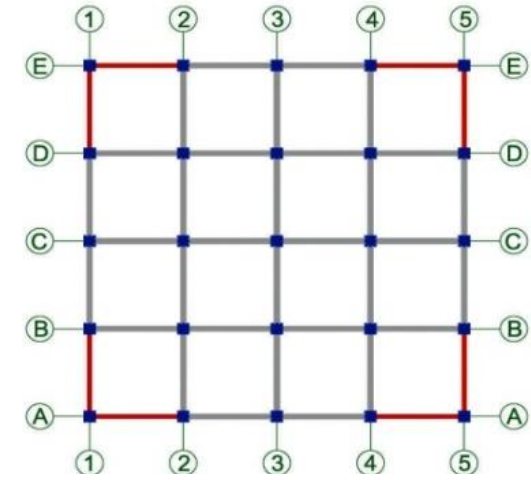

(a) $\mathrm{E}-20$

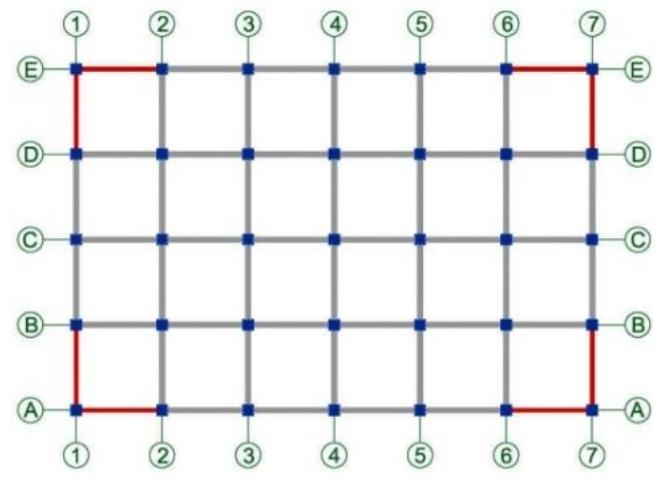

(b) E-30

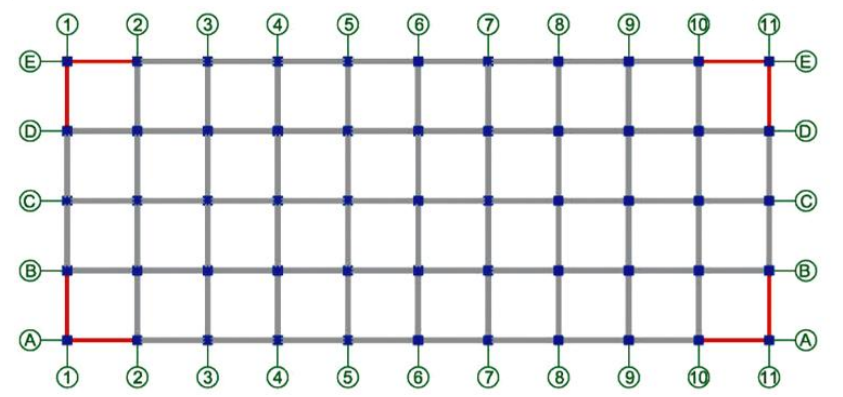

(c) E-50

Fig. 14 Structural plans of parametric model E and its sub models. a) E-20, b) E-30, c) E-50 


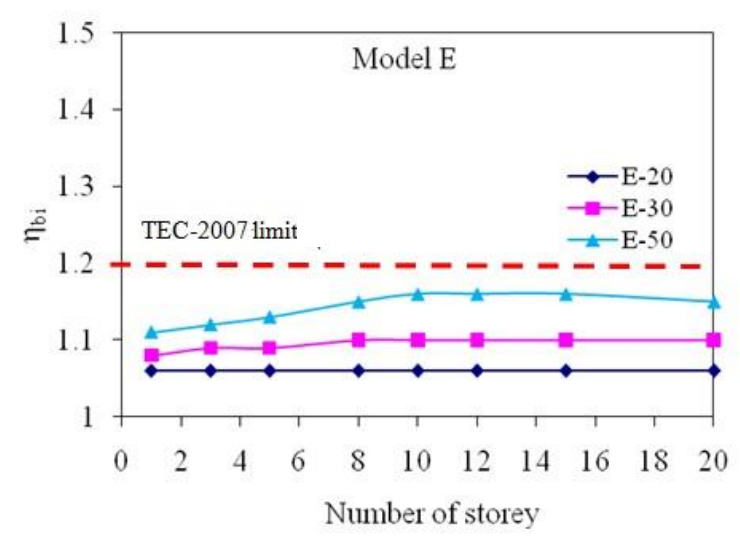

Fig. 15 Changing coefficient $\left(\eta_{\mathrm{bi}}\right)$ with the number of storey and different sub-model

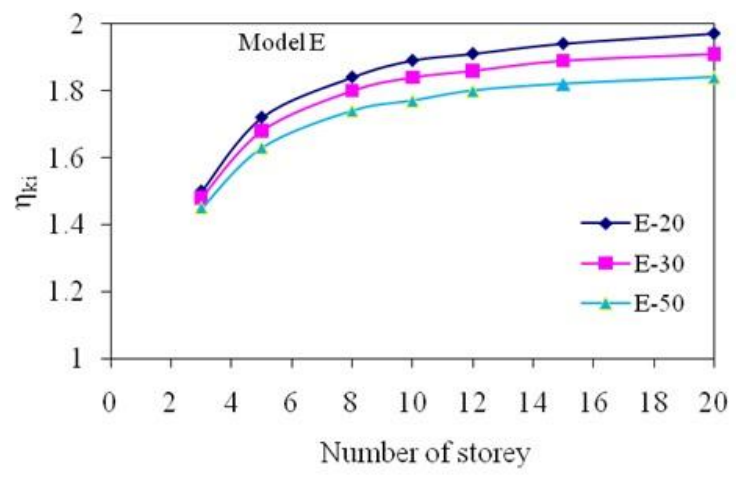

Fig. 16 Changing coefficient $\left(\eta_{\mathrm{ki}}\right)$ with the number of storey and different sub-model

Stiffness irregularity coefficient $\left(\eta_{\mathrm{ki}}\right)$ shows normal value range in the parametric models of E. The range varies between 1.50 and 1.97 in E-20, 1.48 and 1.91 in E-30 and 1.45 and 1.84 in E-50 (Fig 16). There is a decrease in the maximum stiffness irregularity coefficient from E-20 to E-50 (Fig 16). As evidence, while maximum stiffness irregularity in E-20 is 1.97, it is 1.84 in parametric model E-50. Moreover, it is observed that if the number of storey in parametric model E increases, the maximum soft storey coefficient will gradually increase. As the coefficients remain under the limit coefficient of 2.00 , the soft storey coefficient is agreeable.

\subsection{Model of F: shear-frame system (4)}

The parametric model $\mathrm{F}$ is designed as a shear-frame system like in parametric model $\mathrm{D}$. The only difference between the parametric model $\mathrm{D}$ and $\mathrm{F}$ is the central rigid core. It is removed from the parametric model F (Fig. 17). I-shaped shear walls are located in the middle of the outer axis of the structure. The results were given in Figs. 18-19.

The analysis show that the maximum value of effective storey drift in parametric model F-20 varies between 0.34 and $10.90 \mathrm{~mm}$, it varies between 0.45 and $12.75 \mathrm{~mm}$ in F-30 and 0.62 and 
$14.60 \mathrm{~mm}$ in F-50. The limit values of interstorey drifts and second order effect are not exceeded. These values also gradually increase from one-storey model to 20 -storey model. Moreover, they are all increase from ground floor to upper floors in parametric models of F-20, F-30 and F-50.

The maximum torsional irregularity coefficient $\left.\left(\eta_{\mathrm{bi}}\right)\right)$ is 1.07 in F-20, 1.10 in F-30 and 1.16 in F-50. It is observed that if the number of storey of the parametric models in F increases, the maximum torsional irregularity coefficients will increase. Besides, it increases from parametric model F-20 to F-50. As the number of axis increase, the torsional irregularity coefficients will increase. There is not torsional irregularity in parametric model $\mathrm{F}$.

Stiffness irregularity coefficient $\left(\eta_{\mathrm{ki}}\right)$ has acceptable coefficients in all parametric models of $\mathrm{F}$. The coefficients vary between 1.45 and 1.87 in F-20, 1.44 and 1.84 in F-30 and 1.41 and 1.78 in F50. There is a decrease in the maximum stiffness irregularity coefficient from F-20 to F-50. There is no stiffness irregularity in F-50. The maximum stiffness irregularity coefficient is obtained as 1.87 in the 20-storey sub-model of F-20. Furthermore, it is noticed that if the number of storey increase, the maximum soft storey coefficient will gradually increase in each sub-model of parametric model F.

Stiffness irregularity coefficient $\left(\eta_{\mathrm{ki}}\right)$ has acceptable coefficients in all parametric models of $\mathrm{F}$. The coefficients vary between 1.45 and 1.87 in F-20, 1.44 and 1.84 in F-30 and 1.41 and 1.78 in F50. There is a decrease in the maximum stiffness irregularity coefficient from F-20 to F-50. There is no stiffness irregularity in F-50. The maximum stiffness irregularity coefficient is obtained as 1.87 in the 20-storey sub-model of F-20. Furthermore, it is noticed that if the number of storey increase, the maximum soft storey coefficient will gradually increase in each sub-model of parametric model $\mathrm{F}$.

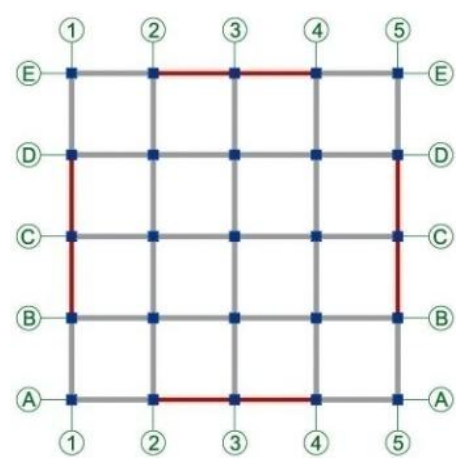

(a) F-20

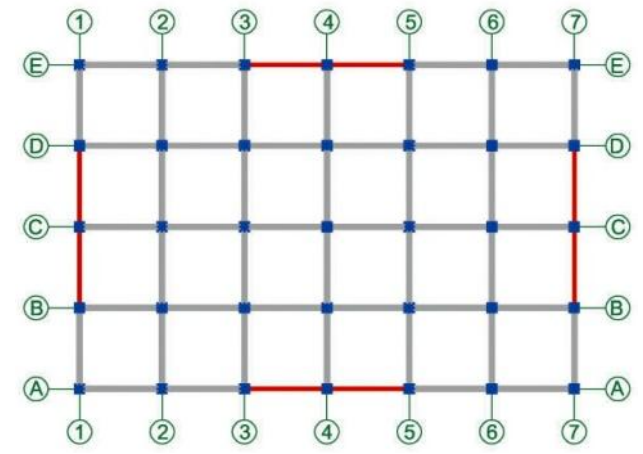

(a) F-30

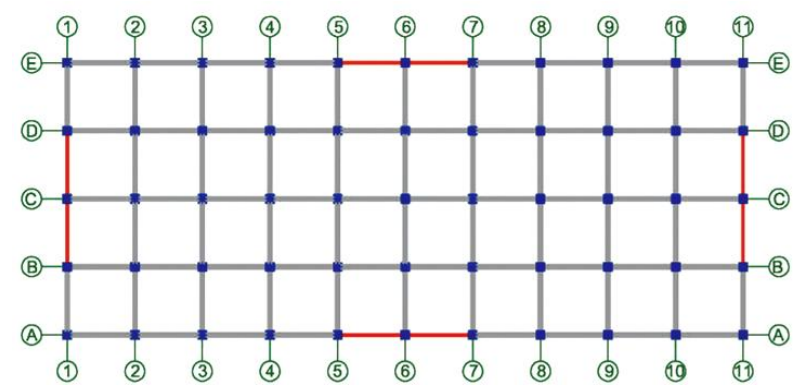

(c) F-50

Fig. 17 Structural plans of parametric model F and its sub models. a) F-20, b) F-30, c) F-50 


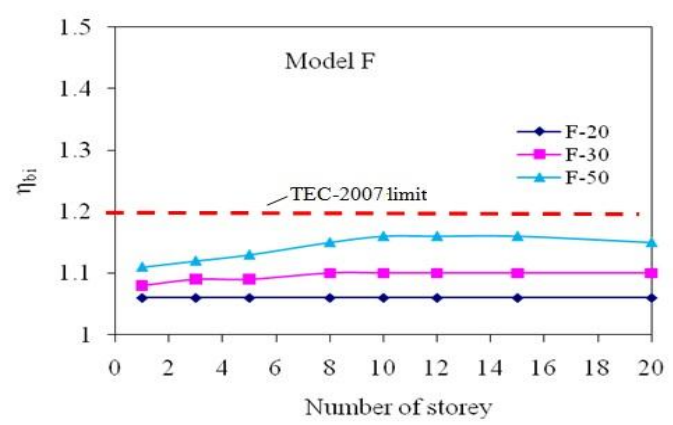

Fig. 18 Changing coefficient $\left(\eta_{\mathrm{bi}}\right)$ with the number of storey and different sub-model

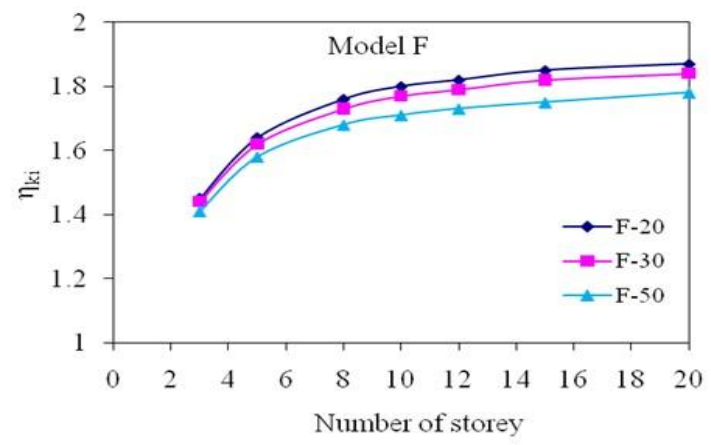

Fig. 19 Changing coefficient $\left(\eta_{\mathrm{ki}}\right)$ with the number of storey and different sub-model

\section{Summary and discussions}

In the study, a set of six main models and their sub-models which were generated by changing the number of axis number, storey and the R/C structural system type were analyzed in terms of earthquake behavior on bases of the structural irregularities. All models were created as to have both symmetric plan geometry and rigidity distribution. The aim of this case was to investigate the seismic behavior of completely symmetrical structures in terms of plan geometry and rigidity distribution. $\mathrm{R} / \mathrm{C}$ structural system types which are commonly constructed in Turkey are grouped and the models are created for each type. The results were discussed according to the several criteria containing torsional irregularity coefficient, soft storey coefficient, effective storey drifts, interstorey drifts and second order effects. On the basis of the carried out numerical analysis for the different type of $\mathrm{R} / \mathrm{C}$ models the following conclusions could be drawn up:

- It is observed that the models designed as frame systems (parametric model A) shows acceptable torsional irregularity coefficients. However, a central rigid core added to the system, the structures expose to high torsional irregularity coefficients like in sub models of B.

- If the number of axis increases, the torsional irregularity coefficients increase in all parametric models and their sub models (Fig. 20). On the other hand, it is observed that while the torsional irregularity shows a regular increase between the own stories of each different storied parametric models, in contrast in some models it shows a regular decrease or an unbalanced increase or decrease under earthquake loading. 
- The parametric model $\mathrm{C}$ which consists of a central rigid core and L-shaped shear walls on the corners of the building show similar seismic performance with the parametric model $\mathrm{D}$ which have I-shaped shear walls in the middle of the outer axis of the structure with a central rigid core. While the maximum torsional irregularity coefficient is obtained 1.17 in parametric model C, it is 1.16 in parametric model D. On the other hand, while the parametric model C-20 has soft storey irregularity, the parametric model D does not have soft storey irregularity. Moreover, the parametric model $\mathrm{E}$ which consists of $\mathrm{L}$-shaped parametric model without a central rigid core behaves similarly against earthquake loads with the parametric model $\mathrm{F}$ which consists of I-shaped shear walls in the middle of the outer axis of the structure without a central rigid core.

- The models which have shear walls in the middle of the outer axis of the structure shows better seismic performance in terms of torsional irregularity and soft storey irregularity coefficients rather than the models which have shear walls on the corners of the structure. Moreover, locations of the shear walls in the middle of the outer axis of the structure limits shows positive behavior in terms of effective storey displacements and interstorey drifts.

- It is gained that except the models consisting only frame systems, the soft storey irregularity coefficient will decrease if the number of axis of models increases. While the lowest soft storey irregularity coefficient is observed in sub models of parametric model $\mathrm{F}$, the critical ones are observed in C (Fig 21-23).

- The limit values for effective storey drifts and second order effects have not been exceeded in all the models of the study.

- Increasing rigidity in the structure is not enough by itself to provide earthquake resistance in structures. The usage of shear walls significantly support the earthquake behavior of structures provided that they are correctly placed in the structure even placed symmetrical. For instance, although the parametric model A has not torsional irregularity, the model B expose to the torsion due to the incorrectly placed shear walls. The rigid core is located in the centre of the structure in symmetrical structure close to the gravity centre. Therefore, it causes the torsional irregularity. Shear walls should be located on the outer axis of the structures or distant from the gravity centre as possible.

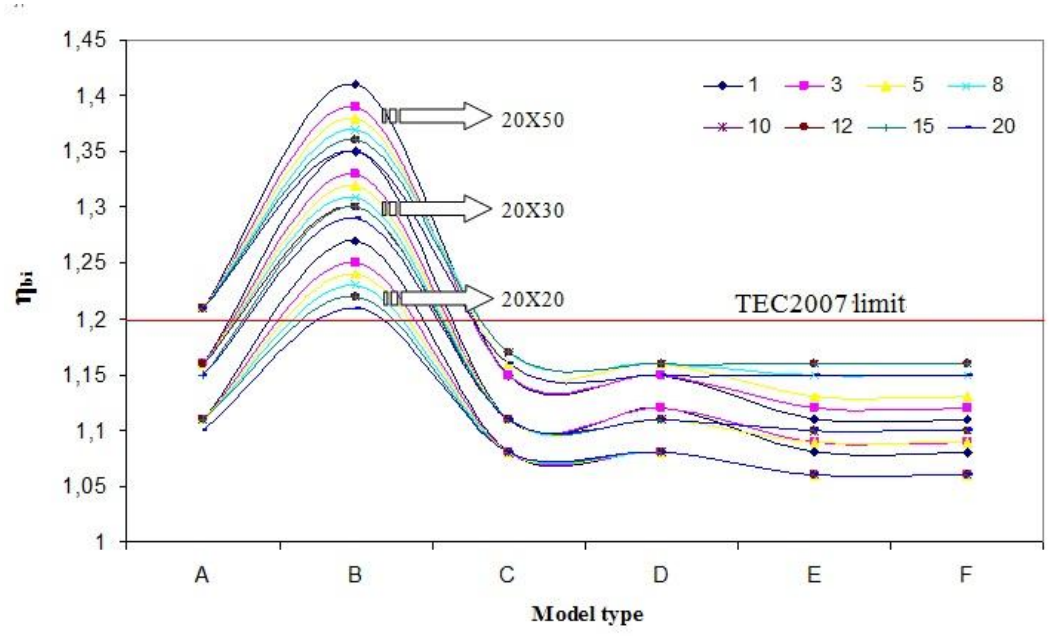

Fig. 20 Changing coefficient $\left(\eta_{\mathrm{bi}}\right)$ with the number of storey and different models 


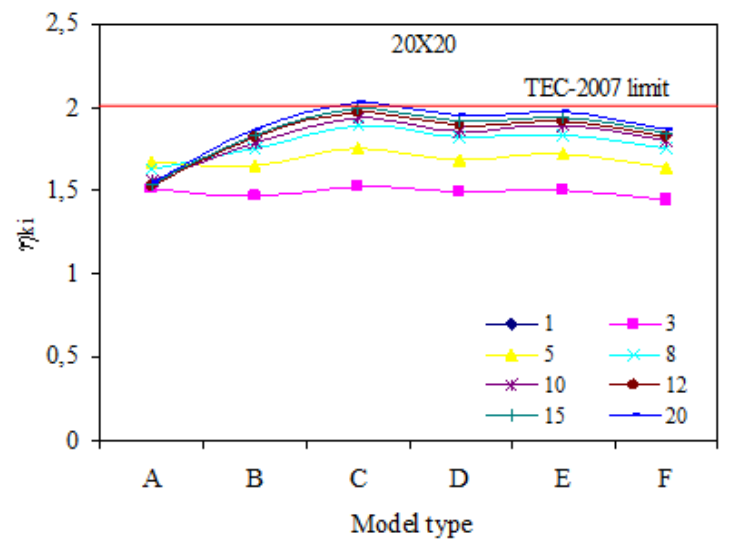

Fig. 21 Changing coefficient $\left(\eta_{\mathrm{ki}}\right)$ with the number of storey and different models

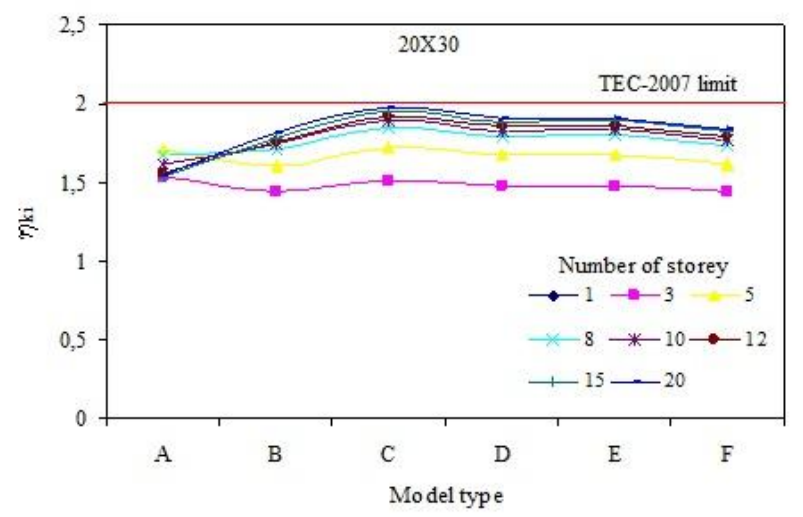

Fig. 22 Changing coefficient $\left(\eta_{\mathrm{ki}}\right)$ with the number of storey and different models

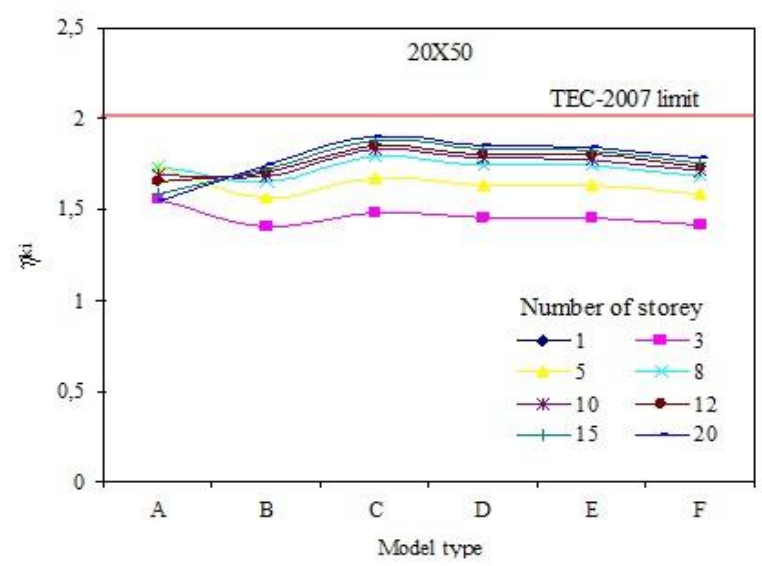

Fig. 23 Changing coefficient $\left(\eta_{\mathrm{ki}}\right)$ with the number of storey and different models 


\section{Conclusions}

This study mainly concentrated on the interaction between R/C frame systems and architectural form. As the aim of the study was to investigate the seismic behavior of completely symmetrical structures, all models are designed having both symmetrical plan geometry and rigidity distribution. Earthquake behaviors of buildings were examined in detail based on the variation in the number of storey, number of axis and configuration of structural members. The general results obtained from the analysis can be summarized as follows:

- It can be clearly deduced from the analyses that shear-frame systems with a central rigid core show better seismic performance than the shear-frame systems without a central rigid core.

- Despite the symmetrical plan geometry and rigidity distribution, structural elements type, their location in the plan and their sufficiency in terms of rigidity, strength and stability according to the each system created in models play the most effective role in earthquake behavior of structures.

- Sufficiency in rigidity of a structure can change according to the number of storey and axis of the structure. Therefore, excessive usage of shear walls does not an indicator of excessive resistant structure against earthquake loads in other words it does not mean the best earthquake resistant building.

- Analyses show that structural irregularities can be observed in completely symmetric buildings in terms of plan geometry and rigidity distribution.

\section{References}

Athanassiadou, C.J. (2008), "Seismic performance of R/C plane frames irregular in elevation", Eng. Struct., 30, 1250-1261.

Bal, I.E., Crowley, H., Pinho, R. and Gülay, F.G. (2008), "Detailed assessment of structural characteristics of Turkish RC building stock for loss assessment models", Soil Dyn. Earthq. Eng., 28, 914-932.

Belmouden, Y. and Lestuzzi, P. (2009), "An equivalent frame model for seismic analysis of masonry and reinforced concrete buildings", Construct. Build. Mater., 23, 40-53.

Cagatay, I.H. (2005), "Experimental evaluation of buildings damaged in recent earthquakes in turkey", Eng. Failure Analysis, 12(3), 440-452.

Cagatay, I.H., Beklen C. and Mosalam K.M. (2010), "Investigation of short column effect of RC buildings: failure and prevention", Comput. Concr., 7(6), 523-532.

Charleson, A. (2008), Seismic Design for Architects: Outwitting the Quake, Burlington: Elsevier, USA.

Chen, W.W., Yeh, Y.K., Hwang, S.J., Lu, C.H. and Chen, C.C. (2012), "Out-of-plane seismic behavior and CFRP retrofitting of RC frames infilled with brick walls", Eng. Struct., 34, 213-224.

Dimova, S. and Alashki, I. (2003), "Seismic design of symmetric structures for accidental torsion", Bull. Earthq. Eng., 1(2), 303-320.

Ganjavi, B., Amiri, J.V., Amiri, G.G. and Amrei, R.S.A. (2007), "Effect of seismic loading patterns on height-wise distribution of drift, hysteretic energy and damage in reinforced concrete buildings", J. Appl. Sci.,7(22), 3431-3441.

IdeCad (2010), İdeYap1, Istanbul, Turkey.

Inan, T. (2010), The interaction of reinforced concrete skeleton systems and architectural form subjected to earthquake effects, Master Thesis, Izmir Institute of Technology.

Inan, T. and Korkmaz, K. (2011), "Evaluation of structural irregularities based on architectural design considerations in Turkey", Struct, Survey, 29(4), 303-319.

Inan, T., Korkmaz, K. and Cagatay, I.H., (2012), “An investigation on plan geometries of RC buildings: with 
or without projections in plan", Comput. Concrete, 9(6), 439-455.

Özmen, G. (2004), "Excessive torsional irregularity in multi-story structures", Technical J., 15, 3131-3144.

Özmen, C. and Unay, A.I. (2007), "Commonly encountered seismic design faults due to the architectural design of residential buildings in Turkey", Build. Environ., 42, 1406 -1416.

Requirements for Design and Construction of Reinforced Concrete Structures (2000), Turkish Standards Institute (TS-500).

Sezen, H., Elwood, K.J., Whittaker, A.S., Mosalam, K.M., Wallace, J.W. and Stanton, J.F. (2000), Structural engineering reconnaissance of the August 17, 1999 Kocaeli (Izmit), Turkey, earthquake, PEER 2000/09, University of California, Berkeley.

Specification for Buildings to be Built in Seismic Zones 2007 (2007), Ministry of public works and settlement, Government of Republic of Turkey.

Stefano De, M. and Pintucchi, B., (2008), "A review of research on seismic behavior of irregular building structures since 2002", Bull. Earthq. Eng., 6(12), 285-308.

Tezcan S.S. and Alhan C. (2001), "Parametric analysis of irregular structures under seismic loading according to new Turkish earthquake code", Eng. Struct., 21, 600-609.

Wang, X., Shan, M., Su, Y., Ge, N. and Chen, H. (2012), "Analysis on efficiency of slot-cutting around RC frame joint for "strong column and weak beam" engineering design", Syst. Eng. Procedia, 3, 381-390.

$C C$ 